\title{
The relevance of biostatistics to the medical student
}

Biostatistics classes can cause many medical students to feel frustrated and frantic. Why does the USMLE include biostatistics questions? Why is biostatistics part of the body of knowledge that is deemed essential and fundamental for the medical student and eventual practitioner. Medical students know why they need to know biostatistics: To help them pass the USMLE! It would be most helpful for them to appreciate-thus motivate them to learn-how understanding biostatistics translates into being a more competent student doctor and medical practitioner in the months, years and decades ahead.

The following is a conclusion of 130 practicing UK physicians that responded to a research questionnaire: "Grounding the teaching of statistics in the context of real research studies and including examples of typical clinical work may better prepare medical students for their subsequent career".

How does biostatistics make medical students better practitioners? This study does not say. Unless one is planning on becoming a researcher or a biostatistician, how does the future physician benefit from studying and mastering biostatistics? This is a question that many perplexed (because of trying to comprehend biostatistics) medical students ask. To reiterate, perceiving the practical role (not just the test-taking role) of biostatistics may better motivate medical students to learn-and to want to learn-the language, purpose and practicality of biostatistics.
Volume 7 Issue 2 - 2018

\author{
Nicholas A Kerna ${ }^{1,2}$ \\ 'College of Medicine, University of Science, Arts and Technology, \\ BWI \\ ${ }^{2}$ Major General Hugh G Robinson Center for Medical Studies, \\ USA \\ Correspondence: Nicholas A Kerna, College of Medicine, \\ University of Science, Arts and Technology, 4288 Youngfield \\ Street, Wheat Ridge, CO 80033, USA, \\ Email nicholas.kerna@usat.edu
}

Received: February 15, 2018 | Published: March 09, 2018

Charles McCulloch, Ph.D., professor and head of Biostatistics at the University of California at San Francisco, states: "Virtually any medical research study uses biostatistics from beginning to end". In a study of practicing physicians, it was reported that biostatistics education was deemed "very and exactly important" by $88.19 \%$ of the respondents; and $27.8 \%$ of the participants did not receive biostatistics education. The following table illustrates the importance that is placed on biostatistics as one climbs the educational "food chain" (Table 1).

Table I The level of importance of biostatistics education in the formal process

\begin{tabular}{|c|c|c|c|c|c|c|c|c|}
\hline \multirow[t]{2}{*}{ Education process } & \multicolumn{6}{|c|}{ The level of importance $(1-5)$} & \multirow{2}{*}{$\bar{x}$} & \multirow{2}{*}{ s.d. } \\
\hline & \multicolumn{6}{|c|}{ Any little middle very exactly } & & \\
\hline \multirow[t]{2}{*}{ Doctorate } & $f$ & 0 & 3 & 25 & 93 & 116 & \multirow{2}{*}{4.36} & \multirow{2}{*}{0.71} \\
\hline & $\%$ & 0 & 1.27 & 10.55 & 39.24 & 48.95 & & \\
\hline \multirow[t]{2}{*}{ Post Graduate } & $f$ & 0 & 4 & 46 & 106 & 81 & \multirow{2}{*}{4.11} & \multirow{2}{*}{0.76} \\
\hline & $\%$ & 0 & 1.69 & 19.41 & 44.73 & 34.18 & & \\
\hline \multirow[t]{2}{*}{ Under graduate } & f & 18 & 45 & 108 & 47 & 19 & \multirow{2}{*}{3.02} & \multirow{2}{*}{0.98} \\
\hline & $\%$ & 7.59 & 19 & 45.57 & 19.83 & 8.02 & & \\
\hline
\end{tabular}

Note Reprinted from The Views of Academic Staff on Biostatistics Education in Health Sciences by Kilic and Celik. Retrieved from: https://www.ncbi.nim.nih.gove/pmc/ articles/PMC3883604/ C20I 3 Int J Health Science (Qassim)

Whether medical students think biostatistics is an unwarranted bore or academic burden, the stark reality is that practicing physicians know that biostatistics is important. In fact, for those physicians who do not possess biostatistics proficiency of their own, they rely on friends and colleagues for that know-how and those opinions. In medical practice, competence in biostatistics is essential, is practical, is useful, and is utilized and applied-whether it is the physician's own knowledge or insights that are gathered from colleagues; or learned from other sources, as shown in the table below (Table 2).

How do physicians know if the facts that are presented to them are true, or not so true? Unless they fathom the basics of biostatistics, they may fall prey to unscrupulous advertisers and industry promoters, or simply faulty research. They may be fed bogus or biased findings that serve the vested interests of the research group, product company or sales force, but not necessarily fulfill the requirements of the physician or support the needs of the patient.

To be deemed competent, the practitioner must stand between the research and the patient, must stand between the advertisements and the patient, must stand between the hearsay and the patient, must stand between the unscrupulous and unscientific practices and the patient; and must act as the judge per se of what practices, procedures and treatments are beneficial to, and ultimately given to, the patient. The practitioner must be able to stand on their own, and rely upon their own reason and judgment, for there will not always be a higher authority close at hand to defer to. Grasping the principles of biostatistics gives the clinical medical student the independence and the opportunity to think clearly and to draw rational conclusions. 
Table 2 The source of current biostatistics knowledge of the participants

\begin{tabular}{lll}
\hline Information source & f & $\%$ \\
\hline Lessons received during the education process (undergraduate-post graduate) & 149 & 62.90 \\
Personal (individual) efforts & 128 & 54.00 \\
Friends who are knowledgeable on the subject & 109 & 46.00 \\
Course-seminars ect. given by private and/or public experts & 40 & 16.90 \\
Scientific meetings (congress, symposium ect.) & 29 & 12.20 \\
Other & 2 & 0.80 \\
\hline
\end{tabular}

Note Reprinted from The Views ofAcademic Staff on Biostatistics Education in Health Sciences by Kilic and Celik. Retrieved from:https://www.ncbi.nim.nih.gove/pmc/ articles/PMC3883604/ @20I 3 Int J Health Science (Qassim)

The medical student must develop and nurture the faculty of critical thinking; biostatistics conditions the mind and promotes thought processes in this regard. The lessons that are taught in biostatistics courses give the medical student, and eventual practitioner, the requisite scholarly knowledge and rational tools to evaluate research materials, product advertisements and treatment options; and to choose those which are best suited for the patient. In this way, biostatistics itself becomes part of the patient's treatment and part of the patient's therapy or cure. A solid foundation in biostatistics makes for a better doctor and for better medicine. And, let us not forget, also helps in passing the USMLE!

\section{Acknowledgements}

None.

\section{Conflicts of interest statement}

The author declares that this Opinion was written in the absence of any commercial or financial relationships that could be construed as a potential conflict of interest.

\section{References}

1. Perry A. What is the role of biostatistics in modern medicine? 2011.

2. Kilic I, Celik B. The views of Academic Staff on Biostatistics Education in Health Sciences. Int $J$ Health Sci (Qassim). 2013;7(2):142-149. 